\title{
JUSTIÇA RESTAURATIVA: PRESSUPOSTO PARA UMA POLÍTICA CONSTITUCIONAL CRIMINAL VOLTADA À EFETIVAÇÃO DOS DIREITOS HUMANOS
}

\author{
Marcelino da Silva Meleu ${ }^{1}$ \\ Lenice Kelner ${ }^{2}$
}

\begin{abstract}
RESUMO: O tema trata da justiça restaurativa enquanto política constitucional criminal afeita à concretização dos direitos humanos. Problema de pesquisa: Constitui a justiça restaurativa pressuposto para o estabelecimento de uma política constitucional criminal para a efetivação dos direitos humanos? Objetivo geral: analisar os contornos dos direitos humanos. Específicos: estudar os sentidos da justiça e a (in)suficiência do modelo liberal; verificar a contribuição da justiça restaurativa enquanto política constitucional criminal. $\mathrm{O}$ aprofundamento teórico do estudo baseou-se na pesquisa bibliográfica, utilizando o método sistêmico, preconizado por Niklas Luhmann, que não é indutivo nem dedutivo.
\end{abstract}

Palavras-chave: Direitos Humanos. Solidariedade. Política Constitucional. Política Criminal. Justiça Restaurativa.

\section{RESTORATIVE JUSTICE: PRESUPPOSITION FOR A CONSTITUTIONAL CRIMINAL POLICY AIMED AT THE REALIZATION OF HUMAN RIGHTS}

\begin{abstract}
The theme deals with restorative justice as a constitutional criminal policy aimed at the realization of human rights. Research problem: Is restorative justice a prerequisite for the establishment of a constitutional criminal policy for the realization of human rights? General objective: to analyze the contours of human rights. Specific: to study the meanings of justice and the (in) sufficiency of the liberal model; to verify the contribution of restorative justice as a constitutional criminal policy. The theoretical depth of the study was based on the bibliographical research, using the systemic method, recommended by Niklas Luhmann, that is neither inductive nor deductive.
\end{abstract}

Keywords: Human Rights. Solidarity. Constitutional Policy. Criminal Policy. Restorative Justice.

\footnotetext{
${ }^{1}$ Pós-Doutor em Direito Público. Professor concursado na Universidade Regional de Blumenau - FURB, com lotação no Centro de Ciências Jurídicas. Líder do Grupo de Pesquisa CNPq "Direitos Fundamentais, Cidadania e Justiça'. Pesquisador em Direitos Humanos; Direitos Fundamentais; Cidadania; Solidariedade; Teorias e Efetividade da Justiça. Advogado. Mediador certificado pelo Ministério da Justiça.

${ }^{2}$ Doutora em Direito Público. Professor do quadro permanente da FURB (Blumenau/SC). Membro do Grupo de pesquisa CNPq: "Direitos Fundamentais, Cidadania e Justiça". Pesquisadora em Criminologia e Controle Penal. Direitos Humanos; Direitos Fundamentais; Cidadania; Solidariedade; Política Constitucional e Justiça Restaurativa.
} 


\section{INTRODUÇÃO}

O presente trabalho pretende abordar, de forma sucinta, o modelo de justiça restaurativa e sua contribuição para o estabelecimento de uma política constitucional de enfrentamento dos conflitos penais, a partir do reconhecimento dos direitos humanos como um mínimo ético, para a sustentabilidade social.

A relevância temática, e assim, sua justificativa está fundamentada na crescente disposição estatal de recrudescimento da política de encarceramento. Uma política fundada na aplicação de penas cruéis e infamantes, que longe de ressocializar, auxilia na propagação da reincidência, porquanto excludente, já que não dá voz aos envolvidos diretamente e indiretamente no conflito, no caso, vítima, ofensor e comunidade.

Tal reconfiguração se mostra essencial, porquanto o conflito constitui elemento de alta complexidade, uma vez que, inerente ao convívio social. A sociedade em sua complexidade, demanda outras espécies de concepções de justiça, para além daquelas típicas do monismo estatal, como a versão retributiva, e que, reforce uma observação solidária, que pregue uma cooperação dos conflitantes e destes com o ambiente.

Outras práticas sociais, de indivíduos, movimentos, associações, através das quais é criada uma ordem de convivência, em razão de compartilhamentos gerais fundados sobre informações autonomamente adquiridas e convergentes nas finalidades, que também pode conter ameaças de eficácia excludente de direitos fundamentais são necessárias, por isso, a importância de perspectivas dadas por uma política constitucional.

Com a perspectiva de se analisar outras práticas para a observação do ambiente criminal, se elegeu a justiça restaurativa como uma das espécies do gênero política constitucional, porquanto, essa perspectiva de justiça permite que se observe os novos sentidos para o enfrentamento dos conflitos criminais, com observância dos pressupostos do Estado Democrático de Direito. Nesse sentido, elege-se como problema de pesquisa a seguinte indagação: Constitui a justiça restaurativa pressuposto para o estabelecimento de uma política constitucional criminal para a efetivação dos direitos humanos?

O aprofundamento teórico do estudo pauta-se na pesquisa bibliográfica, consubstanciada nas leituras de diversas obras, utilizando-se do método científico sistêmico, preconizado por Niklas Luhmann, que não é indutivo nem dedutivo, uma vez que pretende 
descrever os sistemas (aberto e fechado) e sua relação com o ambiente para formalizar a pesquisa.

Diante deste questionamento, o presente trabalho objetiva estudar em um primeiro momento, o conteúdo dos direitos e a noção de solidariedade, para em seguida, perscrutar as concepções de política constitucional criminal e a justiça restaurativa. Desta forma, parte-se de um estudo que busca observar uma ressignificação do sentido de justiça, que promova o encontro entre os atores e tratamento digno daquele que se envolveu em um evento delituoso.

\section{DIREITOS HUMANOS E SOLIDARIEDADE}

A ideia de Direitos Humanos é assim tão antiga como a própria história das civilizações, tendo logo se manifestado em distintas culturas e em momentos históricos sucessivos, na afirmação da dignidade da pessoa humana, na luta contra todas as formas de dominação e exclusão e expressão, visando a asserção de uma vida comunitária e do princípio da legitimidade (TRINDADE, 2003). Para alguns, representam uma constante histórica cujas raízes estão voltadas às instituições e pensamentos do mundo clássico. Enquanto que, para outros, a ideia dos Direitos Humanos nasceu com a afirmação cristã da dignidade moral do homem como pessoa. (LUNÕ, 1995).

O conceito de Direitos Humanos, veio proporcionar a decomposição do conceito de Direito, pois, afinal, possui uma função própria e insubstituível. "Seu advento foi o correlato do eclipse ou da perversão, na filosofia moderna individualista, da ideia de justiça e de seu instrumento, a jurisprudência. Ela tinha por finalidade a mensuração de justas relações" (VILLEY, 2007, p. 163).

Lunõ (1995) traz presente uma conceituação dos Direitos Humanos que é tratada por Bobbio, para a qual, e na maioria dos casos, essa expressão não está realmente definida ou está em termos insatisfatórios. Tendo em mente a sua abordagem, podem distinguir-se três tipos de definições de Direitos Humanos: (1) Tautológico, que não fornece elementos novos que caracterizam tais direitos. Assim, por exemplo, os direitos do homem são aqueles que correspondem ao homem pelo fato de ser um homem; (2) Formais, que não especificam o conteúdo desses direitos, limitando-se a alguma indicação do status desejado ou proposto. Do tipo de: os direitos do homem são aqueles que pertencem ou devem pertencer a todos os homens, e dos quais nenhum homem pode ser privado. (3) Teleológicas, em que apelam a certos

Rev. de Criminologias e Politicas Criminais | e-ISSN: 2526-0065 | Porto Alegre | v. 4 | n. 2 | p. 138-158 | Jul/Dez. 2018 
valores finais, susceptíveis de diversas interpretações: os direitos do homem são os essenciais para o desenvolvimento da civilização.

Além disto, com o intuito de promover a paz mundial entre as nações, proteger os direitos humanos e as liberdades, bem como os direitos civis do indivíduo, em 24 de outubro de 1945, foi fundada a Organização das Nações Unidas (ONU). (MEIRELLES, 2011). E, após três anos, em 10 de dezembro de 1948, surgiu a Declaração Universal dos Direitos Humanos, tendo como foco reconhecer a dignidade inerente a todos os membros da família humana, assegurando que "ninguém será sujeito a interferências na sua vida privada, na sua família, no seu lar ou na sua correspondência, nem a ataques e a sua honra e reputação" (DECLARAÇÃO UNIVERSAL DE DIREITOS HUMANOS, 1948).

Conforme relata Supiot (2007, p. 237),

Se a Declaração de 1948 fez assim, a personalidade jurídica entrar na lista dos direitos humanos, não foi somente porque ela é tecnicamente necessária para o gozo de todos os outros direitos. A razão essencial está alhures. Sob o império do cientificismo, o próprio Ocidente veio a acreditar que a única realidade do Homem era de natureza biológica, e que a personalidade jurídica era, portanto, uma pura técnica de que se podia dispor a vontade. Mas os horrores do nazismo acabavam de mostrar que essa redução do homem ao seu ser biológico redundava em fazer da sociedade um mundo darwiniano submetido apenas à lei do mais forte. Foi por isso que a Declaração Universal fez dessa personalidade o objeto de um direito universal e imprescritível.

Esta declaração contribuiu para espalhar no nível normativo e doutrinal a expressão Direitos do Homem. Autores dos séculos XVII e XVIII afirmaram a prioridade dos direitos naturais subjetivos em relação à lei objetiva positiva, mas nenhum deles pretendia, o que teria sido uma contradição, para manter o primado dos direitos natural subjetivo sobre a lei natural objetiva, mesmo que enfatizassem o antigo ou ocupados preferencialmente ou exclusivamente desses. (LUNÕ, 1995).

Já com a criação da Declaração de Direitos da Virgínia, em 1776 e da Declaração dos Direitos do homem e do Cidadão da França, em 1789 ocorre o reforço instrumental da noção de Direitos Humanos. (MACHADO, 2003). Todavia, para além da definição contida nos instrumentos, a expressão Direitos Humanos aparece, geralmente, relacionada a outras denominações que, em princípio, parecem designar realidades muito próximas, senão para uma mesma realidade. Sendo estas expressões prescritas a partir da inclusão dos direitos naturais, direitos fundamentais, direitos individuais, direitos subjetivos e liberdades públicas. Em relação 
a conjunção de direitos naturais, fica notável que os mesmos correspondem ao homem pelo simples fato de direitos existentes e civis, aqueles que correspondem ao homem pelo fato de ser um membro da sociedade. (LUNÕ, 1995).

O termo direitos fundamentais aparece na França a partir de um movimento político e cultural que culminou com a Declaração dos Direitos do Homem e do Cidadão, de 1789. Estes direitos fundamentais articularam o sistema de relações entre o Estado, como base de toda a ordem legal-política. Para alguns doutrinadores, são estes Direitos Humanos positivados nas Constituições estatais, através de princípios, que resumem a concepção do mundo e informam a ideologia política de cada sistema jurídico. Estes direitos indicam o horizonte dos objetivos sociopolíticos a serem alcançados, estabelecendo a posição jurídica dos cidadãos nas suas relações com o Estado ou entre eles. (LUNÕ, 1995). No que tange ao domínio das leis, em um contexto de direitos fundamentais clássicos, que garantem a autonomia privada dos membros da sociedade, o direito passa a legitimar-se como um meio de assegurar, de forma equânime, a autonomia pública e privada. (MELEU, 2014).

No campo dos direitos e garantias fundamentais, destacam-se importantes incisos do art. $5^{\circ}$, da Constituição Federal brasileira que assegura os direitos e deveres individuais e coletivos. O próprio caput do art. $5^{\circ}$, ao estabelecer que todos são iguais perante a lei, sem distinção de qualquer natureza, é norma garantidora do princípio da igualdade, que proíbe toda e qualquer discriminação. (PIOVESAN, 2012).

Contudo, a imprecisão da figura do direito subjetivo, objeto de um desafio aberto por parte do realismo escandinavo e da doutrina kelseniana, indica a dificuldade que também existe aqui para delinear claramente as relações desta noção com a dos Direitos Humanos. Para aqueles que sustentam que os direitos subjetivos são expressão de todos os atributos da personalidade, os Direitos Humanos constituem uma subespécie daqueles, pois, seriam os direitos subjetivos diretamente relacionados às faculdades de autodeterminação do indivíduo (LUNÕ, 1995). Nota-se ainda, ao observar o direito subjetivo como uma figura jurídica afim com a dos direitos do homem e da personalidade, todos representativos, no seu desenvolvimento teórico, do individualismo. No Direito Medieval, a noção do direito subjetivo é relacionado ao conceito de privilégio. (LAFER, 1991).

Habermas (2002) alerta que a ideia de Direitos Humanos, que se anuncia no Direito, como liberdades de ação subjetivas e iguais, não pode ser colocado como uma barreira externa ao legislador soberano e, ao mesmo tempo, não pode ser considerado como um requisito 
funcional instrumentalizado para atender os fins deste legislador. Por isso, o autor aduz que para fins de garantir a expressão correta daquele instituto, há de se “[...] considerar o procedimento democrático a partir de ponto de vista da teoria do discurso: sob condições do pluralismo social e de visões [...]" pois, nessa perspectiva seria “[...] o processo democrático que confere força legitimadora ao processo de criação do direito.” (HABERMAS, 2002, p. 299300).

É notável o significado histórico de todos estes documentos abordados, porém, é preciso perceber que eles não conseguiram tratar, efetivamente, dos direitos de todos os homens, sendo que em muitos estados norte-americanos continuou lícita a posse de escravos até depois da Guerra-Civil (KAUFMANN, 2013).

Souza (2011) chega a afirmar que todos nós, de alguma forma, somos violentos, a diferença é que os bárbaros deixam a violência fluir sem controle, enquanto que outros à medida que vão se civilizando, conseguem suprimir este lado violento. Nesse sentido, apesar de já haver expressos inúmeros documentos e declarações, foi só após as grandes calamidades, que começou o esforço de reconstrução dos Direitos Humanos como paradigma e referencial ético a orientar a ordem internacional contemporânea. E, assim, ao cristalizar a lógica da barbárie, a Segunda Guerra Mundial simbolizou a ruptura com relação aos Direitos Humanos, significando no Pós-Guerra a esperança de reconstrução destes mesmos direitos. (PIOVESAN, 2006).

Consequentemente, com o esforço da reconstrução dos Direitos Humanos, fez surgir o paradigma e referencial ético a orientar a ordem internacional contemporânea. Afinal, foi no exato momento em que os seres humanos se tornaram supérfluos e descartáveis que entrou em vigor a destruição, em que, cruelmente, se aboliu o valor da pessoa humana, tornando necessária a reconstrução dos Direitos Humanos como paradigma ético capaz de restaurar a lógica do razoável. Desse modo, a barbárie do totalitarismo significou a ruptura do paradigma dos Direitos Humanos, por meio da negação do valor da pessoa humana como valor fonte do Direito. (PIOVESAN, 2006).

No Brasil, a Constituição Federal de 1988, que simbolizou o marco jurídico da transição democrática e da institucionalização dos Direitos Humanos no país, demarcou a ruptura com o regime autoritário militar instalado em 1964, refletindo o consenso democrático "pós-ditadura". Após vinte e um anos de regime autoritário, objetiva a Constituição resgatar o Estado de Direito, a separação dos poderes, a Federação, a Democracia e os direitos fundamentais, à luz do princípio da dignidade humana. (PIOVESAN, 2006). 
Porém, percebe-se, que no século XX (continuando no século XXI), apesar de se verificar um vasto progresso na ciência e na tecnologia, este veio acompanhado, tragicamente, de destruição e crueldade, aumentando a prosperidade de um lado, bem como, a pobreza extrema de outro. Os horrores deste século agonizante, de dimensões apocalípticas, excedem os de séculos precedentes, pois, apesar de tantos avanços tecnológicos tem-se, em paralelo, os horrores de duas guerras mundiais, do holocausto, do gulag, dos conflitos internos contemporâneos, dos atos de genocídio em distintas partes do mundo (TRINDADE, 1997).

Villey (2007, p. 173) alerta que “[...] nunca se viu na história que os direitos humanos fossem exercidos em proveito de todos. O problema com os direitos humanos é que ninguém poderia tirar partido deles senão em detrimento de alguns homens." Mas, para que ocorra uma mudança, toda e qualquer forma que vise enfrentar a violência e o desrespeito aos Direitos Humanos, depende da relação entre Estado e sociedade, e que, este venham propiciar a valorização dos aspectos participativos da cidadania, tendo assim um comprometimento com a valorização dos Direitos Humanos, sendo este um componente essencial para uma sociedade democrática (SOUZA, 2011).

Diante disto, vê-se a necessidade de abordar os Direitos Humanos e o princípio moral do homem como fim em si mesmo. Há ainda uma outra ligação que deve ser observada entre os Direitos Humanos e a dignidade humana, entendendo-se uma dignidade que é inere ao homem, concedida independentemente de outro qualificativo, seja biológico, social ou moral. Um referencial mais consistente do conceito de dignidade humana é dado pelos processos de emancipação e combate à discriminação, nos quais, além da reivindicação de proteção, reivindica-se que o homem seja reconhecido em sua dignidade com independência de seu posto social, credo, cor e sexo, para ser, verdadeiramente, livre. (KAUFMANN, 2013).

A liberdade sempre foi o princípio aglutinador da luta pelos Direitos Humanos, até o ponto em que, durante muito tempo, a ideia de liberdade, em suas diversas manifestações, foi identificada como a própria noção de Direitos Humanos. Apesar de haver inúmeros estudos sobre a existência de direitos naturais desenvolvidos dentro de um dos movimentos mais decididos da crítica radical da tradição metafísica, a liberdade foi reconhecida como o único direito natural. No que se refere à igualdade, o Direito Humano mais importante em nosso tempo, pode ser considerado como um postulado que apoia toda a construção teórica e jurídica positiva dos direitos sociais. (LUNÕ, 1995), afinal os Direitos Humanos consistem, precisamente, em faculdades inerentes à própria natureza do homem e, portanto, inalienáveis 
pelos seus titulares e imprescritíveis, cuja violação é uma agressão direta à própria personalidade humana. Daí o seu caráter inviolável, especialmente, para aqueles que exercem o poder. (LUNÕ, 1995).

Assim sendo, é necessário que haja o respeito aos princípios básicos dos Direitos Humanos para que os mesmos sejam garantidos, não permitindo a intolerância às desigualdades sociais, razão de se proporcionar políticas públicas que venham efetivar a cidadania. (SOUZA, 2011). Dito isto, nota-se a importância no pensar sobre a justiça, pois o atual problema dos Direitos Humanos, não está em fundamentá-los, mas, sim, torná-los efetivos. Assim, Bobbio (1992), em relação aos direitos do homem, aborda que, hoje, a dificuldade não é de justificálos, mas o de protegê-los, especialmente, em um cenário globalizado.

Todavia, para uma reflexão sobre os valores comuns da humanidade, deve-se evitar, como aponta Supiot (2007), todo e qualquer fundamentalismo, considerando que a interpretação fundamentalista dos direitos do Homem pode assumir três faces distintas: (1) Messianismo, trata-se de um fundamentalismo por que propõe uma interpretação ao pé da letra dos direitos do Homem criados por sociedades desenvolvidas para as sociedades em desenvolvimento, desconsiderando qualquer interpretação possível de ser aplicada por estas com base em suas diversidades; (2) Comunitarismo, é um fundamentalismo porque encoraja a superioridade do Ocidente e nega outras civilizações em nome do relativismo cultural instituindo a pertença racial como fundamentalismo identitário, pondo de um lado homens livres destinados a governarem sua própria vida e do outro homens marcados desde o nascimento por sua pertença a uma comunidade diferente. (Afro-Americanos, HispânicosAmericanos, Asian-Americanos que vivem nos EUA); (3) Cientismo, o fundamentalismo se encontra, aqui, na presunção da ciência de interpretar os direitos do Homem de acordo com os ensinamentos que ela promulga (a partir da biologia ou da economia, por exemplo), pois, para ela a questão normativa deriva do domínio dos fatos e o Direito deve simplesmente abraçar essas normas por ela comprovadas. Se vê aqui o quanto os direitos do Homem são passiveis de serem sujeitos a regras consideradas ainda mais fundamentais.

Toda essa interpretação fundamentalista dos direitos do Homem coloca os países "aquém EUA" diante de uma encruzilhada onde escolhem transformar-se, renunciando ao que são ou permanecer como são, renunciando a qualquer transformação (SUPIOT, 2007). Para que seja possível abrir a interpretação dos direitos do Homem à contribuição de todas as civilizações, o autor aponta que seria necessária a criação de mecanismos institucionais 
próprios, com vistas a favorecer uma negociação básica entre os sistemas dogmáticos, dado que estes não dialogam, somente negociam, além de dotar de força jurídica todos os acordos que daí resultarem.

Para concretizar a esperança de uma composição de Direitos Humanos, que revele a inclusão das perspectivas do Sul e Norte, do Ocidente e Oriente, em um cenário globalizado, importa conceber o direito e o direito constitucional em particular, em instrumento prescritivo que se transforma em instrumento descritivo da realidade, porquanto, essa configura a essência de um novo olhar para a efetivação dos Direitos Humanos, dado que, "de nada servirão as definições jurídicas, que podem ser aplicadas a todos os papéis assinados pelo povo [...] proclamando-as ‘constituições', seja qual for seu conteúdo, sem penetrarmos na sua essência.”. (LASSALLE, 2012, p. 13).

Contudo, para enfrentar uma interpretação jurídica, que busque a essência dos Direitos Humanos e o papel da solidariedade, enquanto direito fundamental de terceira dimensão, com vistas à proteção de grupos humanos (povo, nação), se insere aqui a proposta do estudo do Direito como "política constitucional".

Como observou Zagrebelsky (1998), o Direito é um conjunto de materiais de construção, porém a construção em concreto não é obra da Constituição enquanto tal, mas de uma 'política constitucional' que se aplica às possíveis combinações destes materiais e, que significa estudar não apenas as técnicas jurídicas e disciplinares de interpretação e aplicação das disposições constitucionais (como "normatividade constitucional", segundo a fórmula de H. Heller), mas sobretudo as políticas, de qualquer conteúdo e nível (privado, comercial, tributário, cultural, pedagógico, econômico, local, nacional, supranacional, internacional etc.), que contribuem para promover ou condicionar a atuação das Constituições e, portanto, do Direito, como desenhos da convivência e da vida em comunidade (CARDUCCI, 2016).

\section{POLÍTICA CONSTITUCIONAL CRIMINAL E JUSTIÇA RESTAURATIVA}

Para Carducci (2016), a política constitucional não é outra coisa que não o conjunto de ações e atividades práticas, culturais, educativas, sociais, comunicativas, jurisprudenciais, legislativas, econômicas, políticas, que alimentam práxis de uso das regras e princípios jurídicas, em geral, e constitucionais em particular, mas sobretudo a unidade do sentido da Constituição no seu conjunto, uma vez que, a política é um conjunto de práticas sociais, de

Rev. de Criminologias e Politicas Criminais | e-ISSN: 2526-0065 | Porto Alegre | v. 4 | n. 2 | p. 138 - 158 | Jul/Dez. 2018 
indivíduos, movimentos, associações, através das quais é criada uma ordem de convivência, em razão de compartilhamentos gerais fundados sobre informações autonomamente adquiridas e convergentes nas finalidades, que também pode conter ameaças de eficácia excludente de direitos fundamentais, advindas não somente da política, mas "de todos os subsistemas autônomos que dispunham de uma dinâmica expansiva própria.” (TEUBNER, 2016, p. 254).

Tal política, para a pretensão do presente trabalho, deve revelar "uma teoria dos direitos fundamentais sociologicamente fundada, que compreende os direitos fundamentais como instituição" (TEUBNER, 2016, p. 297), bem como, um distanciamento da tradição metodológica, ainda hoje, dominante nos sistemas romano-germânicos, que partindo de uma base hegeliana, confere ao Estado centralidade no discurso constitucional. Ou seja, acompanhando Otero (2007), tal proposta assume o compromisso de fazer uma leitura personalista do fenômeno constitucional, onde as instituições encontram na pessoa humana viva e concreta, o fundamento do Poder Político e da Constituição. Neste ambiente, a Constituição é fruto de uma longa investigação em torno da articulação entre a história da filosofia políticoconstitucional e a evolução da tutela jurídico-constitucional da pessoa humana.

Só um modelo político de Estado de Direitos Humanos, alicerçando a edificação de uma democracia humana, permite no presente, uma garantia jurídico-constitucional eficaz dos direitos fundamentais inerentes ao ser humano. (CANOTILHO, 2003). Tal reflexão, visa contrapor à ideia de que os Direitos Humanos se transformaram em um mito concretizado nas sociedades pós-modernas, porquanto, como alerta Douzinas (2009, p. 384), naquelas, muitos ainda "sofrem violações em maior ou menor grau nas mãos dos poderes que proclamaram seu triunfo".

No campo criminal, uma política constitucional solidária passa pela ressignificação do modo de se compreender e efetivar a justiça. Mas, qual o sentido da justiça adotar, a partir deste contexto?

Muitos foram os teóricos que contribuíram para a compreensão do sentido de justiça. $\mathrm{Na}$ grécia antiga, Aristóteles a considerava como a mais elevada virtude, porquanto nela, se resumiria toda excelência moral, que visando sempre o bem do outro, não só se manifesta na convivência entre as pessoas, uma vez que, para o estagirista, justiça é considerada o justo meio. O homem justo é aquele que além de saber o que é justo pratica atos justos, é na ação que o ser humano mostra a justiça, Justitia est constans et perpetua voluntas jus suum cuique tribuendi, porém, segundo Aristóteles (2009), a simples noção de igualdade não é suficiente para 
expressar o critério de justiça, posto que, o dar a cada um o mesmo não é medida ideal. A proporcionalidade é elemento essencial nos diversos tipos de repartição, assim, é indispensável se recorrer a este critério, diante de situações desiguais.

Para ele, a justiça é um termo ambíguo, ou seja, possui muitos significados e sentidos semelhantes, porém não iguais, o que justifica a importância de se estudar as modalidades de justiça. O pensador grego, após reconhecer a ambiguidade do vocábulo justiça, sugere a existência de uma justiça universal e outra particular. A primeira, também conhecida como justiça total ou integral, consiste, basicamente, na observância da lei, a virtude que acompanhava as outras, fazendo analogia com o que ele acreditava ser a estrela Vésper ${ }^{3}$. Esta estrela estava sempre no mesmo lugar, não importava se era dia ou se era noite, então Aristóteles comparava a justiça a esta estrela. É uma virtude que acompanha todas as demais virtudes.

Já na justiça particular ocorre a particularização do termo justiça que se subdivide, para os fins aqui pretendidos ${ }^{4}$, em Distributiva e Corretiva. A Distributiva consiste na repartição das honras e dos bens entre os indivíduos, de acordo com o mérito de cada um e respeitando o princípio da proporcionalidade a ser aplicado pelo legislador, porquanto, se as pessoas não são iguais também não terão coisas iguais. A Corretiva baseia-se em um critério objetivo e impessoal com o objetivo de restabelecer o equilíbrio rompido entre as partes. Visa regular relações mútuas, as medidas são feitas apenas no campo objetivo, não há espaços para a relatividade, pressupõe uma condição de paridade, de coordenação, à uma ideia de divisão perfeita, de igualdade aritmética. $\mathrm{O}$ valor justo corretivo será sempre reclamado quando, nas relações humanas, houver uma parte a que se atribua uma quantia maior de vantagem e menor de desvantagem em detrimento de outra parte que, por sua vez, sofre a injustiça por receber mais daquilo que lhe é maléfico e menos daquilo que lhe é benéfico. Nesse caso, a função do juiz será retirar daquele que se apropriou de porção maior do que é bom, redistribuindo-a ao outro, ou atribuir mais do que é ruim aquele que se esquivou de fazê-lo por sua própria vontade. Na teoria de Aristóteles o juiz sempre será o mediador de todo processo de aplicação de justiça corretiva, porquanto a ele é atribuída a função de aplicar a equidade, considerando-a como uma medida de correção da justiça legal, ou seja, um instrumento sob o qual se constrói a justiça.

A classificação atual da justiça decorre ainda da distinção aristotélica entre a justiça distributiva e corretiva - a esta divisão, Santo Tomás (2012) acrescentou a justiça geral, que

\footnotetext{
${ }^{3}$ Que, com o passar do tempo, descobriu-se que se tratava de um planeta (Vênus).

${ }^{4}$ Uma vez que não se desconsidera que as subdivisões propostas por Aristóteles, compreendem outras nuances.
} 
consiste na contribuição dos membros da comunidade para o bem comum - porém, aquelas contribuições da antiguidade, modernamente a centralidade da discussão da justiça, ainda reside na tensão entre o viés liberal e o social. No que tange ao modelo liberal, não há como não falar de justiça, sem atentar para as contribuições de John Rawls, que partindo de uma abordagem contratualista pelas influências de Locke e Rousseau, vê a possibilidade de a justiça ser boa para uns e para outros não.

Rawls (1993), na fase inicial de sua teoria, afirma que esta consiste, basicamente, na conciliação entre os dois princípios da modernidade: a liberdade (valor individual) e a igualdade (valor coletivo), para que assim se construa uma sociedade justa. Ocorre que, para que isso se efetive, é preciso saber como distribuir bens e direitos. No entanto, para tal distribuição utilizase de regras e princípios e é, exatamente, aqui que se encontra o problema. Não há possibilidade de escolher alguém rico e alguém pobre para fazer as escolhas destas regras e destes princípios, pois cada um deles irá escolher conforme seu interesse particular.

Contudo, quando Rawls (2012) discorre sobre a justiça como equidade, esta equivale ao estado de natureza na teoria tradicional do contrato social. Os princípios da justiça são escolhidos sob um véu de ignorância, garantindo imparcialidade na escolha dos princípios pelo resultado do acaso natural ou pela contingência de circunstâncias sociais; resultado de um consenso ou ajuste equitativo. Todos em situação semelhante; não há como designar princípios de favorecimentos de condições particulares. A posição original é entre os indivíduos tomados como pessoas éticas, isto é, como seres racionais com objetivos próprios e capazes, na hipótese Rawlsiana, de um senso de justiça.

Assim, Rawls propõe uma nova noção de contrato social, onde o que se propõe é retirar as pessoas citadas no exemplo de sua atual situação e colocá-las em uma posição originária onde elas estarão cobertas por um véu da ignorância, estas pessoas não irão saber quem elas são dentro da sociedade (classe social, raça, religião, entre outros). Ele acredita que nesta posição as partes irão formular dois princípios muito importantes e básicos para a construção de uma sociedade justa. O primeiro, diz respeito a liberdade, ela se refere aos Direitos Humanos de primeira geração que são os direitos civil e políticos. Já o segundo, define que as desigualdades econômicas são justas, desde que respeite outros dois princípios: princípio da diferença e o da igualdade de oportunidade. Neste caso a preocupação de Rawls está voltada aos direitos sociais (chamados direitos humanos de segunda geração). 
Segundo a teoria de justiça de Rawls, observando estes critérios, é possível construir uma sociedade justa buscando eliminar as desigualdades inerentes a sociedade moderna e buscando resgatar a igualdade do estado de natureza da teoria tradicional do contrato social. $\mathrm{Na}$ perspectiva de John Rawls a justiça fornece um conjunto único de "princípios de justiça" preocupados, exclusivamente, com a edificação de "instituições justas" (que viessem a constituir a estrutura básica da sociedade), ao mesmo tempo que reclamava das pessoas um comportamento que se conforma-se inteiramente com as exigências de funcionamento dessas instituições.

Adeptos da proposta de justiça social, por sua vez, fazem uma reflexão sobre os desafios decorrentes do fato de existirem razões de justiças plurais e concorrentes, todas com a pretensão de imparcialidade, ainda que diferentes e rivais umas das outras. Nesse sentido, Sen (2012) defende a necessidade de uma compreensão de justiça que se baseie no fato de que a justiça não pode ser indiferente à vida que as pessoas podem viver de fato, motivo pelo qual o mesmo critica a teoria de Rawls quando aponta uma solução única imparcial para a escolha da sociedade perfeitamente justa. Ao contrário de Rawls que se concentra nas utilidades, igualdades e liberdades, Sen encontra-se voltado às liberdades substantivas (capacidades) que permite que uma pessoa escolha a vida que mais valorizar.

Na perspectiva da justiça de Sen, defende-se a existência de algumas inadequações cruciais numa perspectiva que opte por dedicar uma atenção dominante às instituições (com o comportamento humano a ser tomado como necessariamente conforme), em detrimento de se concentrar nas vidas que as pessoas conseguem ir construindo. No campo criminal, especialmente em um país onde se pretenda proporcionar a ressocialização daquelas pessoas que tenham cometido um ato injusto contra a sociedade ou contra outro indivíduo, urge voltar a tematizar o modelo de justiça que melhor se assemelha ao ideal de uma política constitucional criminal ressocializadora, que restaure a harmonia social.

Para tanto, é necessário acabar com os calabouços da modernidade, que se utilizam da prisão como penal e infamante, onde "[...] a prisão se torna então, um braço repressivo do Estado, com a lógica de que quanto mais você punir, mais castigar, mais torna o sujeito um 'bom cidadão'[...]”, como bem descreveu Kelner (2018, p. 189). A autora lembra que a Constituição Federal de 1988, já em seu artigo primeiro dá ênfase ao princípio da dignidade da pessoa humana e da cidadania, perpassando um contexto de preocupação constitucional com a integridade física, moral e bem estar social das pessoas. Ademais, destaca que em seus incisos 
III e XLVII, alínea “a”, é repudiada em âmbito de política constitucional, a tortura, o tratamento desumano ou degradante e vedada as penas cruéis, exceto em estado de guerra (KELNER, 2018).

Mas esta inconformidade com o sentido de justiça criminal tradicional, que ainda se mostra cruel e degradante, sem se preocupar com a efetiva ressocialização dos apenados, não é somente brasileira, tampouco atual. Pesquisas (HOYLE, 2010; WRIGHT, 1996) apontam que desde as décadas de 70 e 80 se discute um amparo cultural para que o desenvolvimento tanto de modelos de justiça voltados para o atendimento das necessidades das vítimas de crimes. Conforme Braithwaite (2002), o interesse pela justiça restaurativa no ocidente ressurgiu a partir de um programa de reconciliação entre vítima e ofensor na cidade de Kitchener, Ontario, no Canadá, no ano de 1974. Tratava-se de programas comunitários que buscavam mediar conflitos entre vítimas e ofensores após a aplicação da decisão judicial.

Assim,

[...] alguns consideram a justiça restaurativa como uma nova técnica social ou programa que pode ser usado no interior dos nossos sistemas de justiça criminal. Outros procuram, em última análise, abolir grande parte do edifício de punição do estado e substituí-lo por respostas baseadas na comunidade que ensinam, curam, reparam e restauram vítimas, autores de crimes e suas comunidades. Outros, ainda, aplicam a visão de cura e restauração a todos os tipos de conflitos e danos. Na verdade, o objetivo final e foco principal, eles sugerem, deveria ser a mudança da maneira como vemos a nós mesmos e nos relacionamos com os outros na vida cotidiana (JOHNSTONE, 2007, p. 5).

Pressupõe uma forma de se tratar o conflito sob outro prisma, a partir do exercício da alteridade e do interesse na ressignificação de laços sociais. Nesse sentido, Ruggiero (2011) destaca ser possível afirmar, que a justiça restaurativa não apresenta vencedores nem perdedores, mas busca apenas a satisfação das necessidades básicas das partes, de modo a proporcionar uma decisão em que os interesses de todos possam ser contemplados. A redução do uso do sistema penal para administrar os conflitos, se mostra necessário, uma vez que, o paradigma a partir do qual encarceramento se apresenta como a melhor solução em termos de punição definitivamente não atingiu seus objetivos, quais sejam, o de responsabilizar e ressocializar infratores, acarretando assim, uma crise de legitimidade do Sistema de Justiça, bem como, o estabelecimento de violência generalizada e o crescimento exponencial dos índices de encarceramento. Para Sica (2007) há muito se vivencia o esgotamento do modelo repressivo de gestão crime.

A partir do padrão da justiça restaurativa o crime é visto como um dano e uma 
violação de pessoas e relacionamentos, portanto, há a obrigação de corrigir os erros, por meio deste modelo de justiça se envolve a vítima, o ofensor e a comunidade na busca de soluções que promovam reparação, reconciliação e segurança. Para Zeher (2008) o crime pode ser observado, tanto por uma lente retributiva, quanto restaurativa. Esta última, identifica as pessoas como vítimas e reconhece a centralidade das dimensões interpessoais, onde as ofensas são definidas como danos pessoais e como relacionamentos interpessoais.

Quadro 1 - Comparativo entre o modelo retributivo e o modelo restaurativo de justiça

\begin{tabular}{|c|c|}
\hline LENTE RETRIBUTIVA & LENTE RESTAURATIVA \\
\hline 1. O crime é definido pela violação da lei & $\begin{array}{l}\text { 1. O crime é definido pelo dano à pessoa e } \\
\text { ao relacionamento (violação do } \\
\text { relacionamento) }\end{array}$ \\
\hline 2. Os danos são definidos em abstrato & 2. Os danos são definidos concretamente \\
\hline $\begin{array}{l}\text { 3. O crime está numa categoria distinta dos } \\
\text { outros danos }\end{array}$ & $\begin{array}{l}\text { 3. O crime está reconhecidamente ligado a } \\
\text { outros danos e conflitos }\end{array}$ \\
\hline 4. O estado é a vítima & $\begin{array}{l}\text { 4. As pessoas e os relacionamentos são as } \\
\text { vítimas }\end{array}$ \\
\hline $\begin{array}{l}\text { 5. O estado e o ofensor são as partes no } \\
\text { processo }\end{array}$ & $\begin{array}{l}\text { 5. A vítima e o ofensor são as partes no } \\
\text { processo }\end{array}$ \\
\hline $\begin{array}{l}\text { 6. As necessidades e direitos das vítimas são } \\
\text { ignorados }\end{array}$ & $\begin{array}{l}\text { 6. As necessidades e direitos das vítimas são } \\
\text { a preocupação central }\end{array}$ \\
\hline $\begin{array}{l}\text { 7. As dimensões inter-pessoais são } \\
\text { irrelevantes }\end{array}$ & 7. As dimensões inter-pessoais são centrais \\
\hline 8. A natureza conflituosa do crime é velada & $\begin{array}{l}\text { 8. A natureza conflituosa do crime é } \\
\text { reconhecida }\end{array}$ \\
\hline 9. O dano causado ao ofensor é periférico & 9. O dano causado ao ofensor é importante \\
\hline $\begin{array}{l}\text { 10. A ofensa é definida em termos técnicos, } \\
\text { jurídicos }\end{array}$ & $\begin{array}{l}\text { 10. A ofensa é compreendida em seu } \\
\text { contexto total: ético, social, econômico e } \\
\text { político }\end{array}$ \\
\hline
\end{tabular}

Fonte: Zeher (2008, p. 174-175)

Neste cenário, "o sistema de justiça criminal cria pressões deturpadoras de muitas outras formas. A justiça criminal é inerentemente orientada para o ofensor. Os acontecimentos, o processo e os principais atores são todos definidos em torno do ofensor.” (ZEHER, 2008, p. 220). Ressignificar esse panorama implica, pela lente da justiça restaurativa, atender às necessidades imediatas, especialmente as da vítima. Da mesma forma, a justiça restaurativa deveria buscar identificar necessidades e obrigações mais amplas, de modo que o processo, na medida do possível, deveria colocar o poder e a responsabilidade nas mãos dos diretamente 
envolvidos: a vítima e o ofensor (sem desconsiderar a participação da comunidade).

Uma política criminal, neste contexto, deve tratar do relacionamento vítima-ofensor facilitando sua interação e a troca de informações sobre o acontecido, sobre cada um dos envolvidos e sobre suas necessidades, da mesma forma, que deve se concentrar na resolução dos problemas, tratando não apenas das necessidades presentes, mas das intenções futuras, prospectando um novo cenário, subvertendo assim, a noção de justiça como figura burocrática e opressora nas mãos do Estado.

Nesse sentido, Zehr e Towes (2006, p. 422) destacam que:

Desde o primeiro momento em que uma infração ocorre, são os especialistas que descrevem e atribuem sentido ao evento. Após a descoberta do crime, os policiais são geralmente os primeiros a chegar ao local do crime. O policial provavelmente escreverá um relatório com a descrição da infração, com base nas versões da vítima e das testemunhas. Ao fazer esse registro, é o policial quem decide qual informação deve ser incluída e criar uma tradução dos eventos que passa a ser a verdade inicial da infração. A infração então passa para as mãos de outro conjunto de especialistas neutros, os advogados, juízes e peritos forenses. Os advogados analisam e selecionam as histórias fornecidas pelo infrator, vítima e testemunhas, a fim de determinar qual informação é mais próxima da verdade relevante e útil, para os fins de acusação ou defesa do réu. Eles determinam também qual a acusação da qual o réu deve defenderse. São eles quem avaliam qual o caminho mais eficaz na acusação ou defesa do réu e aceitam o rejeitam os acordos judiciais em nome de seus clientes. A informação é apresentada a um juiz, e algumas vezes a um júri que, por sua vez determinam o que é relevante e tomam a decisão final em relação ao caso.

Introduzir os principais atores do conflito, na produção da justiça que propicie uma restauração das relações, pressupõe romper com o monopólio da fala, do poder e do dever de dizer, de modo a propiciar a fala de outros interessados, além dos profissionais e órgãos da justiça estatal, porquanto, já há elementos para se reconhecer uma jurisdição comunitária (MELEU, 2014), pois a sociedade possui legitimidade para declarar seus próprios direitos, e condições para auxiliando o aparato político da sociedade, a implementar, no Brasil, o compromisso inserido com o advento do Estado Democrático de Direito de, tanto no âmbito interno, quanto internacional, no que tange a pacificação social. 


\section{CONSIDERAÇÕES FINAIS}

Em conclusão parcial é possível constatar que, se de um lado, os Direitos Humanos fornecem ao mundo globalizado um arsenal que confere as tábuas da lei universal de que ele precisa, de outro, tal arsenal só atende aos direitos de parcela da sociedade mundial.

Para os dominadores, a percepção dos Direitos Humanos revela um 'mito concretizado' e assim, não se discute sua efetivação. Ocorre que, em que pese o entendimento daqueles, se verifica, em pleno século XXI, violações em maior ou menor grau, deste mínimo ético para a convivência em sociedade.

No campo penal, um sistema que ainda fomente penas cruéis e degradantes, além de não atentar para aquela condição, ainda reforça a reincidência criminal, comprometendo a própria sociedade em um círculo vicioso, que além de isolar, esquece que aquele que em um dado momento cometeu um ilícito penal, retornará para o convívio social. No Brasil, a ressocialização restou normatizada, todavia, ainda não completamente implementada.

Deste modo, urge uma reflexão sobre o conteúdo dos Direitos Humanos e sua contribuição para a implementação de uma política constitucional, no âmbito criminal. Para tanto, há que se evitar todo e qualquer fundamentalismo, seja baseado em um messianismo, um comunitarismo ou cientificismo. Uma interpretação dos direitos do Homem, que o conceba em corpus dogmático, um recurso comum da humanidade, para permitir engendrar uma outra visão, que possibilite uma hermenêutica dos direitos do Homem possível a todas as civilizações, sem a necessidade de regredir com seus valores ao ceder a uma interpretação fundamentalista.

Todavia, para que seja possível abrir a interpretação dos direitos do Homem à contribuição de todas as civilizações, seria necessária a criação de mecanismos institucionais próprios para favorecer a negociação básica entre os sistemas dogmáticos, de modo a respaldar um universo físico humanamente suportável. Como um dos mecanismos possíveis, aponta-se, acompanhando Supiot, a revisitação ao princípio da solidariedade, que revele a inclusão das perspectivas do Sul e Norte, do Ocidente e Oriente, de crédito como forma de direitos individuais (como expresso na Declaração Universal, de 1948) e de débito, posto que, imponha ao indivíduo o dever de preservar e fortalecer a solidariedade social e nacional (como dispõe a Declaração Africana).

Tal proposta pressupõe uma discussão profunda e sofisticada dos Direitos Humanos, pelos afetos, pelos amores e solidariedade entre as pessoas, desde uma perspectiva não 
exclusivamente normativista, e, que conceba o sentido de justiça social, para além do modelo apenas retributivo não dialoga com os anseios da sociedade atual e, assim, tampouco com a perspectiva de tratamento adequado dos conflitos. Isso porque aquele modelo cala os envolvidos e transfere a gestão das situações conflituosas para o Estado, que ainda vinculado a matriz monista, possui o protagonismo da jurisdição.

Romper com este paradigma, impõe conceber, a partir de uma perspectiva de jurisdição comunitária, ou seja, que a perspectiva de se dizer o direito não está alicerçada tão somente na função estatal, para assim, implementar um modelo de justiça voltado para o atendimento das necessidades das vítimas de crimes, mediador dos conflitos entre vítimas e ofensores. Assim, pressupondo uma forma de se tratar o conflito sob outro prisma, a partir do exercício da alteridade e do interesse na ressignificação de laços sociais.

Nesse sentido, se mostra a concepção de justiça restaurativa, um modelo que não apresenta vencedores nem perdedores, mas busca apenas a satisfação das necessidades básicas das partes, de modo a proporcionar uma decisão em que os interesses de todos possam ser contemplados, que identifica as pessoas como vítimas e reconhece a centralidade das dimensões interpessoais, onde as ofensas são definidas como danos pessoais e como relacionamentos interpessoais, posto que há muito vivenciamos o esgotamento do modelo repressivo de gestão crime.

Uma discussão de justiça nesse sentido, que conceba o direito e o direito constitucional em particular como instrumento prescritivo que se transforma em instrumento descritivo da realidade, só se mostra viável - em um modelo de Estado Democrático de Direito - a partir de um modelo político de Estado de Direitos Humanos, que efetive uma garantia jurídicoconstitucional voltada a efetividade dos direitos fundamentais inerentes ao ser humano.

Para tanto, um primeiro passo reside na construção de políticas constitucionais, ou dito de outra forma, no estabelecimento de um conjunto de ações e atividades práticas, culturais, educativas, sociais, comunicativas, jurisprudenciais, legislativas, econômicas, políticas, que alimentem a práxis de uso das regras e princípios jurídicos, em geral, e constitucionais em particular, mas sobretudo, a unidade do sentido da Constituição no seu conjunto.

Aqui se propõe, como uma das políticas constitucionais possíveis de serem implementadas, a elevação da solidariedade dual (que outorgue direitos, mas imponha deveres) como pressuposto de uma teoria dos direitos fundamentais sociologicamente fundada, que compreenda os direitos fundamentais como instituição e assuma o propósito de fazer uma 
leitura personalista do fenômeno constitucional, onde as instituições encontrem na pessoa humana viva e concreta, o fundamento do Poder Político e da Constituição, que no que concerne aos conflitos criminais, passa pela normatização e implementação da justiça restaurativa, que como referido, por sua vez, devolve aos envolvidos a possibilidade de interação para o tratamento adequado do conflito vivenciado.

Neste ambiente, considerando a Constituição como fruto de uma longa investigação em torno da articulação entre a história da filosofia político-constitucional e a evolução da tutela jurídico-constitucional da pessoa humana, uma revisitação ao princípio da solidariedade, nos moldes aqui propostos, por meio de uma análise policontextural das relações e dos sujeitos envolvidos, a partir da implementação da justiça restaurativa tendente a afastar qualquer tipo de exclusão, no que tange a administração dos conflitos criminais, gera no indivíduo especialmente o ofensor - um sentimento de pertencimento e não de exclusão, que pode contribuir para, de um lado, cumprir o compromisso constitucional com a solução pacifica das controvérsias, e de outro, efetivar o preceito da dignidade da pessoa humana, assim, com a efetivação dos Direitos Humanos.

\section{REFERÊNCIAS}

ARISTÓTELES. Ética a Nicômaco. Trad. António de Castro Caeiro. São Paulo: Atlas, 2009.

BRAITHWAITE, John. Restorative justice and responsive regulation. Oxford: Oxford Press, 2002.

CANOTILHO, J.J.G. Direito Constitucional e Teoria da Constituição. 7 ed. Coimbra: Almedina: Lisboa, 2003

CARDUCCI, Michele; et all. Políticas Constitucionais e sociedade: direitos humanos, bioética, produção do conhecimento e diversidades. Curitiba: Editora Prismas, 2016.

DOUZINAS, Costas. O fim dos direitos humanos. Trad. Luzia Araújo. São Leopoldo: Editora Unisinos, 2009.

HABERMAS, Jurgen. A inclusão do outro: estudos de teoria política. Trad. George Sperger; Paulo Astor Soethe; Milton Camargo Mota. 2. ed. São Paulo: Edições Loyola, 2002.

HOYLE, Carolyn. The Case for Restorative Justice. In: HOYLE, Carolyn; CUNNEEN, Chris. Debating Restorative Justice. Oxford e Portland: Hart Publishing, 2010.

JOHNSTONE, Gerry; VAN NESS, Daniel W. The meaning of restorative justice. In: JOHNSTONE, Gerry; VAN NESS, Daniel W. (Orgs.). Handbook of restorative justice. Cullompton e Portland: Willan Publishing, 2007. 
KAUFMANN, Matthias. Em defesa dos direitos humanos: considerações históricas e de princípio. São Leopoldo: Ed. UNISINOS, 2013.

KELNER, Lenice. A inconstitucionalidade das penas cruéis e infamantes: da voz da criminologia crítica à voz dos encarcerados. Rio de Janeiro: Lumen Juris, 2018.

LAFER. Celso. A reconstrução dos Direitos humanos um dialogo com o pensamento de Hannah Arendt. Ed. SCHWARCZ Ltda. 1991.

LASSALLE, Ferdinand. O que é uma Constituição?. Leme: EDIJUR, 2012.

LUNÕ. Antonio Enrique Perez. Derechos Humanos, estado de derecho y contitucion. Ed. Tecnos. 1995.

MACHADO, Jânio de Souza. O dano moral pela violação ao direito a privacidade: o Mercosul e os direitos humanos. Ijuí. Ed. Unijuí, 2003.

MEIRELLES, Renata. Civilização e barbárie: violações de direitos humanos no Brasil da Ditadura. Anais do XXVI Simpósio Nacional de História - ANPUH • São Paulo, julho 2011 Disponível.

http://www.snh2011.anpuh.org/resources/anais/14/1308093135_ARQUIVO_renata_meirelles _anpuh_14_06.pdf> acesso em março de 2018

MELEU, Marcelino da silva. Jurisdição Comunitária: a efetivação do acesso à justiça na policontexturalidade - Rio de janeiro: Lumen Juris, 2014.

OTERO, Paulo. Instituições Políticas e Constitucionais. Vol. I. Lisboa: Almedina, 2007.

PIOVESAN, Flávia. Temas de direitos humanos / Flávia Piovesan. - 5. ed. - São Paulo : Saraiva, 2012.

RAWLS, John. Justicia como Equidad. 3 ed. Madrid: Tecnos, 2012. , John. Uma teoria da justiça. Lisboa : Presença, 1993.

RUGGIERO, Vincenzo. Penal Abolitionism: a celebration. Oxford: Oxford University Press, 2010 .

SANTO TOMÁS DE AQUINO. Da Justiça. Trad. Tiago Tondinelli. Campinas:Vide Editorial, 2012.

SEN, Amartya. A ideia de justiça. Trad. Denise Bottmann e Ricardo Doninelli Mendes: São Paulo: Companhia das Letras, 2011.

SICA, Leonardo. Justiça restaurativa e mediação penal: o novo modelo de justiça criminal e de gestão do crime. Rio de Janeiro: Lumen Juris, 2007. 
SOUZA, Luís Antônio Francisco. Violência, poder e direitos humanos. Disponível em: . Acesso em: 02 ago. 2017

SUPIOT, Alain. Homo juridicus: ensaio sobre a função antropológica do direito. São Paulo: WMF Martins Fontes, 2007.

TEUBNER, Gunther. Fragmentos constitucionais: constitucionalismo social na globalização. São Paulo: Saraiva, 2016.

TRINDADE, Antônio Augusto Cançado. Tratado de Direito Internacional dos Direitos humanos. Porto alegre, Brasil. 2003.

VILLEY, Michel. O direito e os direitos humanos. São Paulo: WMF Martins Fontes, 2007.

WRIGHT, Martin. Justice for Victims and Offenders: a restorative response to crime. 2. ed. Winchester (Reino Unido): Waterside Press, 1996.

ZAGREBELSKY, Gustavo. Il diritto mite. Legge, diritti, giustizia, Torino, Einaudi, 1992.

ZEHR, Howard. Trocando as lentes: um novo foco sobre o crime e a Justiça. São Paulo: Palas Athena, 2008.

; TOEWS, B. Maneiras de conhecer para uma visão restaurativa de mundo. In: Novas direções na governança da justiça e da segurança. Brasilia: Ministério da Justiça, 2006. 